\title{
Racial Variation in Echocardiographic Reference Ranges for Left Chamber Dimensions in Children and Adolescents: A Systematic Review
}

\author{
Edith D. Majonga ${ }^{1,2,9} \cdot$ Gabrielle Norrish $^{3,4} \cdot$ Andrea M. Rehman $^{1} \cdot$ Katharina Kranzer $^{1,5} \cdot$ Hilda A. Mujuru ${ }^{6}$. \\ Kusum Nathoo ${ }^{6}$. Jon O. Odland ${ }^{7,8}$. Juan P. Kaski ${ }^{3,4}$. Rashida A. Ferrand ${ }^{1,2}$
}

Received: 22 February 2018 / Accepted: 22 March 2018 / Published online: 4 April 2018

(c) The Author(s) 2018

\begin{abstract}
Echocardiography plays a critical role in the assessment of cardiac disease. Important differences in echocardiographically derived cardiac chamber dimensions have been previously highlighted in different population groups in adult studies, but this has not been systematically studied in children, whose body size changes throughout childhood. The aim of this study was to review the distribution of available reference ranges for the left cardiac chamber dimensions in older children and adolescents. The following electronic data bases were searched: Medline, Embase and Web of Science were searched to identify studies which have established echocardiographic reference ranges of left heart parameters in children and adolescents from 1975 to December 2017. There was no geographical limitation. All results were imported into Endnote. Retrieved articles were screened and data extracted by two independent reviewers. A total of 4398 studies were retrieved, with 36 studies finally included in this review. 29 (81\%) references were from North America and European (Caucasians) populations, with only one study each from Africa and South America. Two-dimensional and M-mode techniques were the most commonly used echocardiography techniques. There were methodological variations in techniques and normalisation of references. Comparison of selected cardiac measures showed significant differences for interventricular septal thickness among Black African, Indian, German and US American children. Available echocardiographic references cannot be generalised to all settings and therefore, there is need for locally relevant reference ranges. Africa and South America are particularly underrepresented. Future studies should focus on developing comprehensive echocardiographic reference ranges for children from different racial backgrounds and should use standardised techniques.
\end{abstract}

Keywords Echocardiography $\cdot$ Reference ranges $\cdot$ Left ventricle $\cdot$ Left atrium $\cdot$ Children

Electronic supplementary material The online version of this article (https://doi.org/10.1007/s00246-018-1873-0) contains supplementary material, which is available to authorized users.

Edith D. Majonga

Edith.Majonga@1shtm.ac.uk

1 London School of Hygiene and Tropical Medicine, London, UK

2 Biomedical Research and Training Institute, Harare, Zimbabwe

3 Centre for Inherited Cardiovascular Diseases, Great Ormond Street Hospital, London, UK

4 Institute of Cardiovascular Science, University College London, London, UK
5 National Mycobacterial Reference Laboratory, Leibniz Research Centre, Borstel, Germany

6 Department of Pediatrics, University of Zimbabwe, Harare, Zimbabwe

7 UiT The Arctic University of Norway, Troms $\varnothing$, Norway

8 Department of Public Health, Faculty of Health Sciences, University of Pretoria, Pretoria, South Africa

9 Clinical Research Department, London School of Hygiene and Tropical Medicine, Keppel Street, London WC1E 7HT, UK 


\section{Introduction}

Echocardiography plays a critical role in the assessment of cardiac structure and function. Due to changes in body size during childhood, the evaluation of cardiac chambers is highly reliant on the availability of reference ranges, the quality of which depends largely on the availability of a representative sample of healthy subjects and the methods employed to collect the data. The definition of what is "normal" varies widely according to age, body surface area (BSA), gender and race $[1,2]$. Studies in adults have shown racial differences in echocardiographically derived cardiac chamber dimensions [1]. These differences may be more apparent in children whose body size changes throughout childhood, but this has not been investigated systematically.

The aim of this study was to systematically review racial distribution and methods used in available echocardiographic reference ranges for left ventricular (LV) and atrial (LA) chamber dimensions in children and adolescents. In addition, we compared values of selected chamber dimensions in different racial groups which have utilised the same methods for any differences.

\section{Materials and Methods}

This review was registered with the international prospective register of systematic reviews (PROSPERO; registration number CRD42015026030).

\section{Type of Studies}

All available studies that reported echocardiographic reference ranges for left cardiac chamber dimensions in healthy children and adolescents, regardless of echocardiographic technique, were considered for inclusion in this review.

\section{Inclusion Criteria and Exclusion Criteria}

Studies including at least 50 healthy participants aged 5-21 years that reported echocardiographic measurements at rest were included. We considered studies written in English and published in peer-reviewed journals. Studies that only included neonates and infants, were conducted at high altitude (>24,000 $\mathrm{m}$ above sea level); involved performing cardiac measures during or after exercise; or were based on autopsy specimens were excluded. Systematic reviews and meta-analyses were also excluded.

\section{Search Strategy}

The following electronic databases were searched: Medline, Embase and Web of Science were searched. In addition, reference lists of selected studies and other systematic reviews were manually reviewed to identify other possible studies for inclusion. The search strategy included the following words: "echocardiography" AND "reference values" OR "normative" OR "reference standards" OR "reference intervals" AND "child" OR "children" OR "adolescent" OR " $z$ score" (Table 1). Appropriate Boolean operators and truncation were used on synonyms. Both medical subjects and

Table 1 Search strategy

\begin{tabular}{|c|c|c|}
\hline Concepts & Set & Search terms \\
\hline Echocardiography & 1 & echocardiography.mp or exp echocardiography/ \\
\hline \multirow[t]{5}{*}{ References } & 2 & exp reference values/or normative.mp \\
\hline & 3 & Reference adj1 values \\
\hline & 4 & Reference adj1 standards) \\
\hline & 5 & Reference adj 1 interval* \\
\hline & 6 & Normal values/or reference value/or reference interval*.mp \\
\hline \multirow[t]{6}{*}{ Children } & 7 & Child.mp or child/ \\
\hline & 8 & adolescent*.mp or exp adolescent/ \\
\hline & 9 & pediatric.mp or pediatrics/ \\
\hline & 10 & Paediatric.mp or paediatrics/ \\
\hline & 11 & Children*.mp \\
\hline & 12 & Infant.mp or exp Infant/ \\
\hline \multirow[t]{5}{*}{ Z-score } & 13 & $\mathrm{z}$-score.mp \\
\hline & 14 & 2 or 3 or 4 or 5 or 6 or 13 \\
\hline & 15 & 7 or 8 or 9 or 10 or 11 or 12 or 13 \\
\hline & 16 & 1 and 14 \\
\hline & 17 & 15 and 16 \\
\hline
\end{tabular}


keywords were used. The same search strategy was adapted for all the listed databases. All results were imported into Endnote X7 (Thomas Reuter).

Duplicate citations were removed. Titles and abstracts from the search results were screened independently by two reviewers (EDM) and (GN). The full texts of potentially eligible studies were obtained and assessed in duplicate using a standardised checklist. Any disagreements about inclusion of studies were resolved by consensus.

\section{Data Extraction and Analysis}

The following data were extracted using a standard data extraction form: author; population studied; sample size; age range; echocardiography technique; parameters measured, and type of normalisation used.

A two-sample Kolmogorov-Smirnov non-parametric test was used to compare distributions of $z$ score $=0$ and 2 for selected cardiac measures of studies which used the same technique for performing echocardiography and the same method for calculation of BSA for normalisation. The selected $z$ score represents the mean predicted value and the upper cut-off for the normal range for a cardiac measure. The null hypothesis was that the compared groups were sampled from populations with identical distributions. Due to multiple testing, the chance of obtaining a significant $p$ value when in fact there is not a true difference between distributions was high. Therefore, we used the Bonferroni adjustment, with a $p$ value $<0.005$ considered significant.

\section{Quality of the Studies}

We adapted the Newcastle-Ottawa Scale for assessing quality of non-randomised studies to suit cross-sectional studies in the systematic review [3]. In our tool, we assigned scores instead of stars (Table 2). The following criteria were used to determine the quality of the studies: representativeness of the sample; sample size; sample selection; standardisation of image acquisition and statistical methods used.

\section{Results}

A total of 4398 citations were retrieved dating from 1975 to June 2017. Of these, 1193 duplicates were removed, and a further 3075 citations were excluded based on title and abstract (Fig. 1). Full texts of a total of 130 studies were reviewed and 36 studies were included. Characteristics of the included studies are in Table 3.

Sixteen (44\%) studies were conducted in North America, followed by Europe $(n=13,36 \%)$ and Asia $(n=5,14 \%)$. Only one study each was conducted in South America (Brazil) and Africa (Zimbabwe). Nine studies reported the race
Table 2 Criteria for assessment of quality of studies using the Newcastle-Ottawa Scale adapted for cross-sectional studies

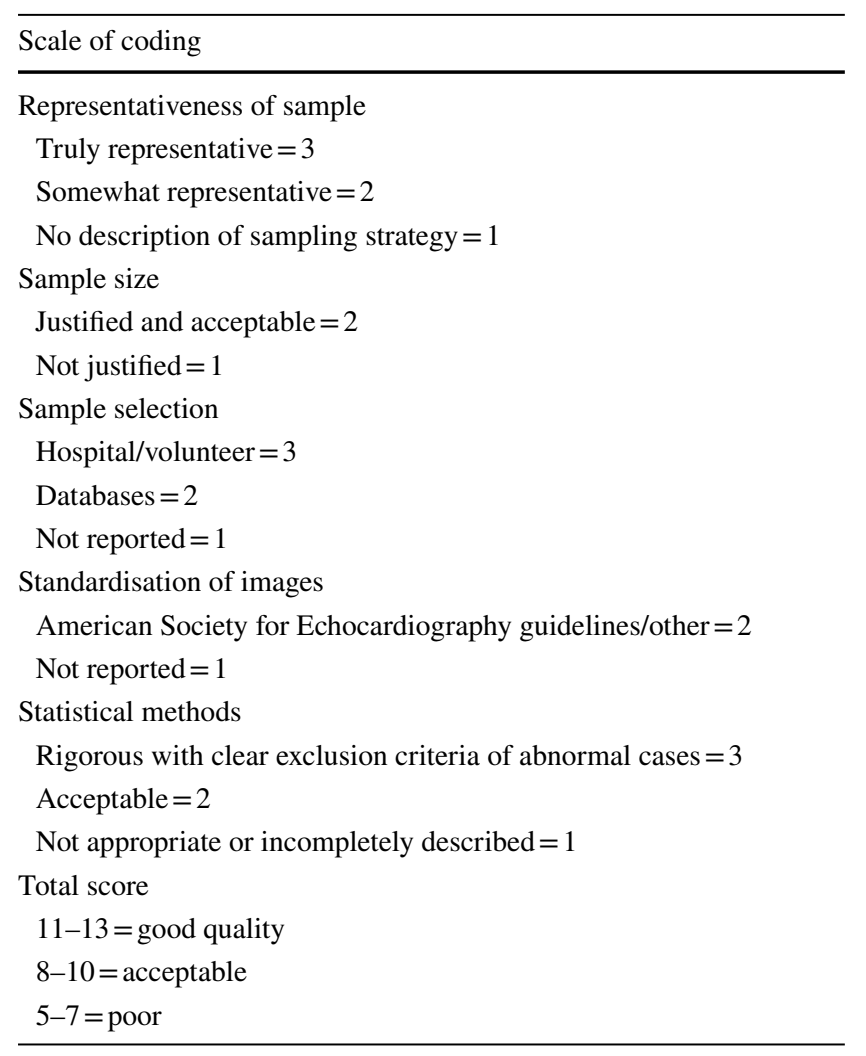

of children studied [6, 8, 9, 19, 23, 25, 33, 38, 39]. Sample sizes of the studies ranged from 95 to 9858 . The quality of the studies was good $(n=16)$ or acceptable $(n=20)$ in all cases.

M-mode and/or two-dimensional (2D) echocardiographic techniques were used in $33(92 \%)$ studies. One study used three-dimensional (3D) echocardiography in addition to M-mode and 2D, another utilised 3D only and a third study used a rarely practiced echocardiographic technique called acoustic quantification [18, 21, 22]. Anthropometric and non-anthropometric measures were used for normalising the results: body surface area (BSA) in 18 studies, height $(n=4)$ [8, 11, 17, 28], weight $(n=3)$ [10, 20, 35], age $(n=2)[14,15]$, and lean body mass $(n=1)$ [7]. The remaining studies used age and heart rate, $(n=1)$; [22] age and BSA, $(n=2) ;[26,37]$ age and height, $(n=1)$; [27] height and BSA, $(n=1)$; [33] weight and BSA, $(n=1)$ [36] and one study used height, BSA and lean body mass [25]. Varying methods to calculate the BSA were used: 12 (33\%) studies used the Dubois and Dubois method, and 4 (14\%) studies used the Haycock. Daubeney et al. used the Boyd method; [24] Saito et al. calculated BSA using the West Nomogram [37] and five studies did not report the method used for calculating BSA [25, 29, 32, 39]. 23 (64\%) studies standardised 


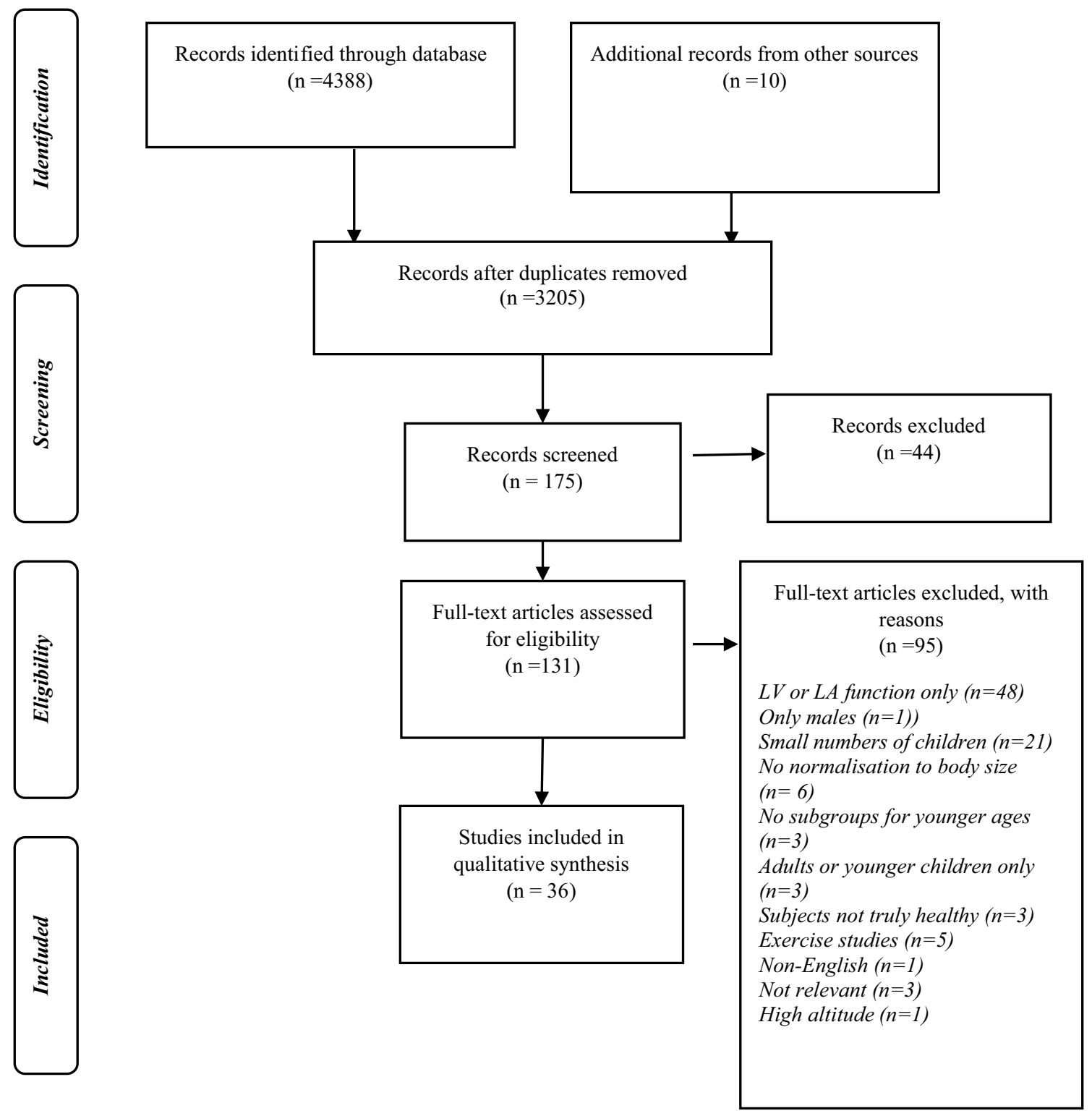

Fig. 1 PRISMA flow diagram for process of selecting included studies

images and performed measurements according to recommendations by the American Society of Echocardiography (ASE); one study used ASE and European Society of Cardiology recommendations and another study used ASE and Penn convention [23, 26]. The remaining studies used other methods of performing measurements, including inner edge to inner edge method in five studies $[24,28,30,31,34]$; trailing edge to leading edge in one study [32]; leading edge to leading edge in one study [35]; standard and Penn convention in one study [37]. Three studies described how they measured parameters without stating a specific convention [21, 38, 39].

\section{Left Ventricular Dimensions}

The following LV dimensions were reported: diameter at end-diastole (LVEDD) and/or end-systole (LVESD), posterior wall and interventricular septal, area, length, volume, LV mass and index. Saito et al. developed references for $\mathrm{LV}$ muscle volume, which is a rarely used measure in clinical practice [37]. 13 studies were from North American children; 12 studies among European children; five studies from Asia and one study each from South American and African children (Table 3). 


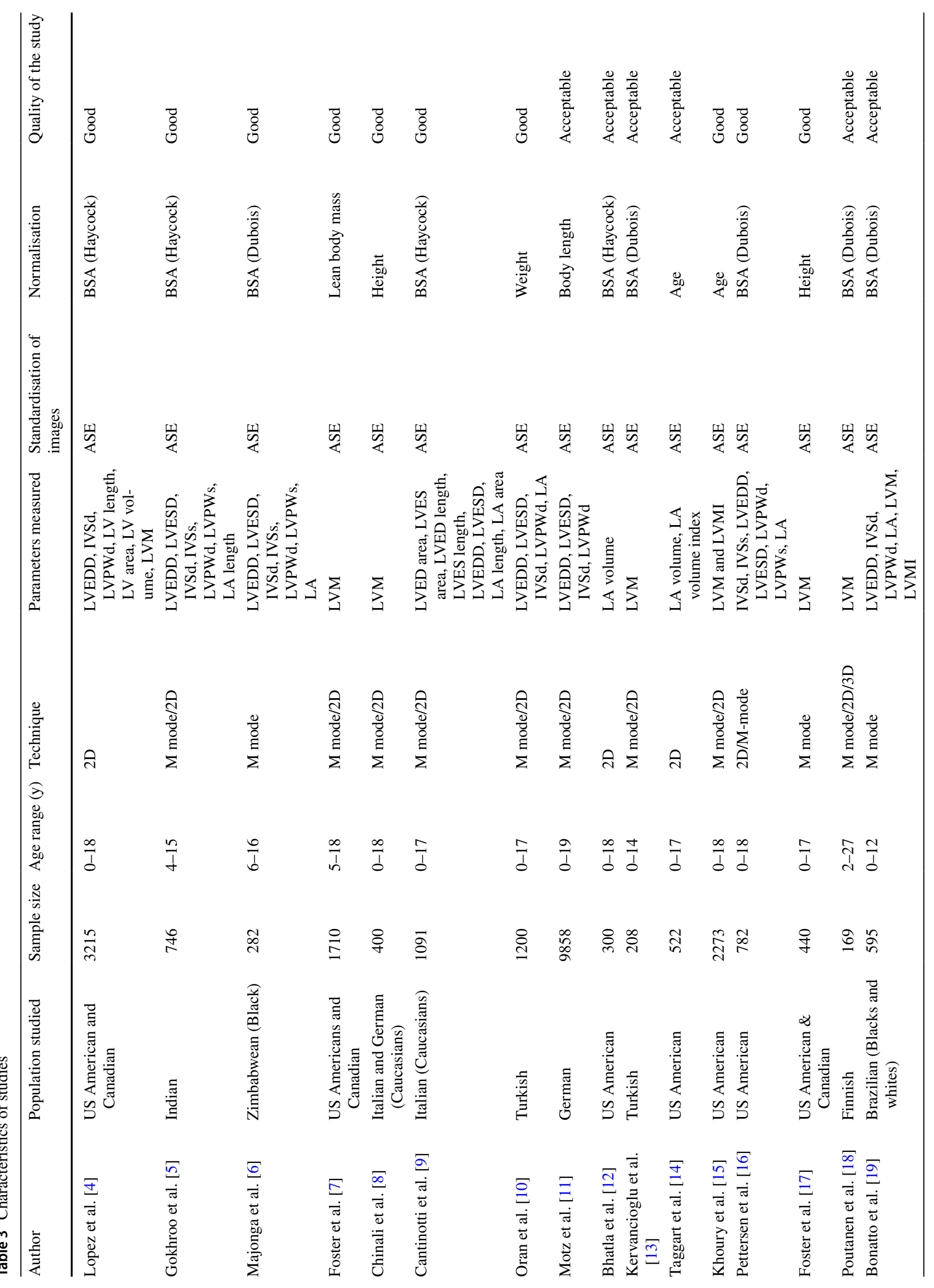




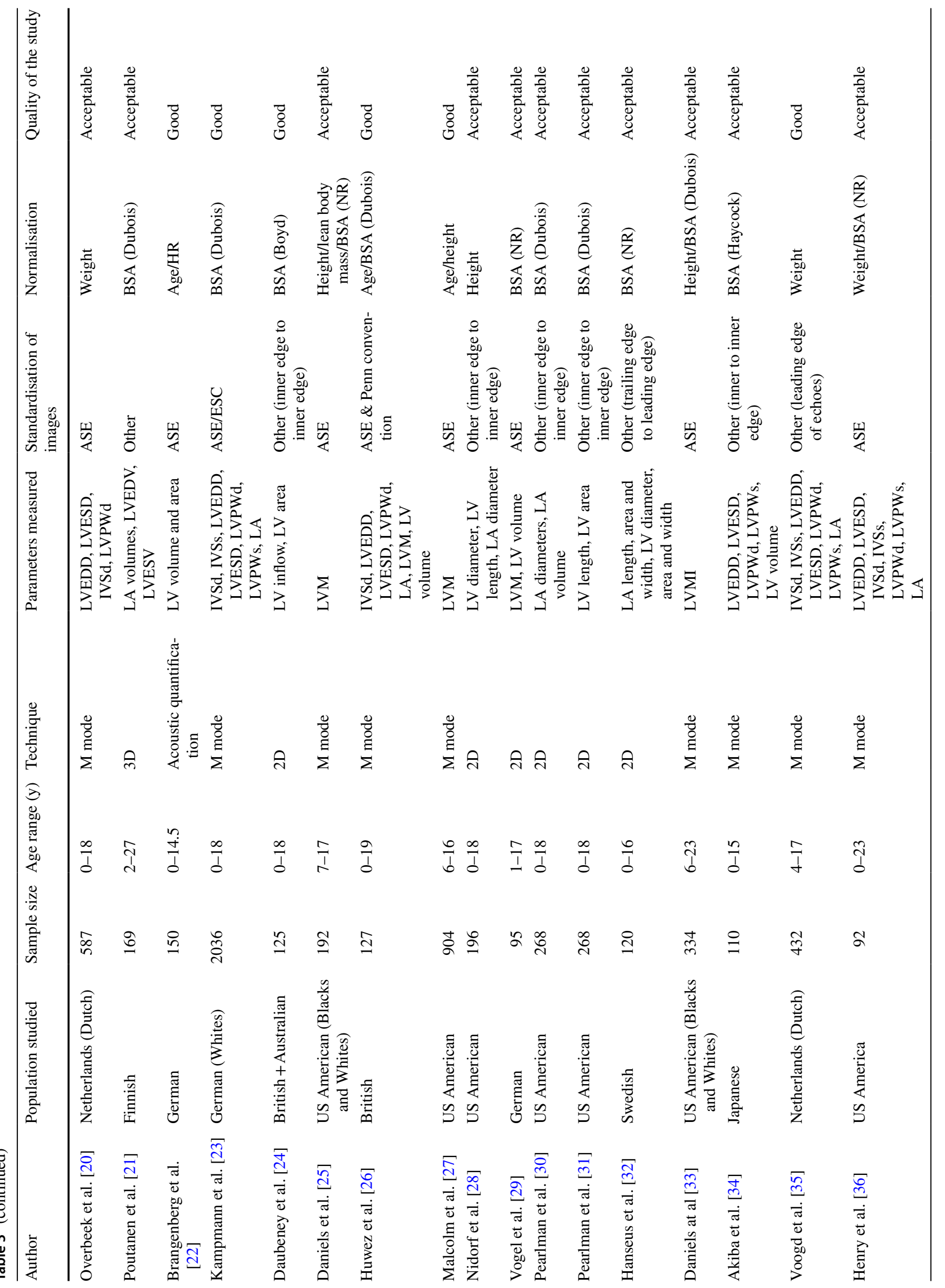




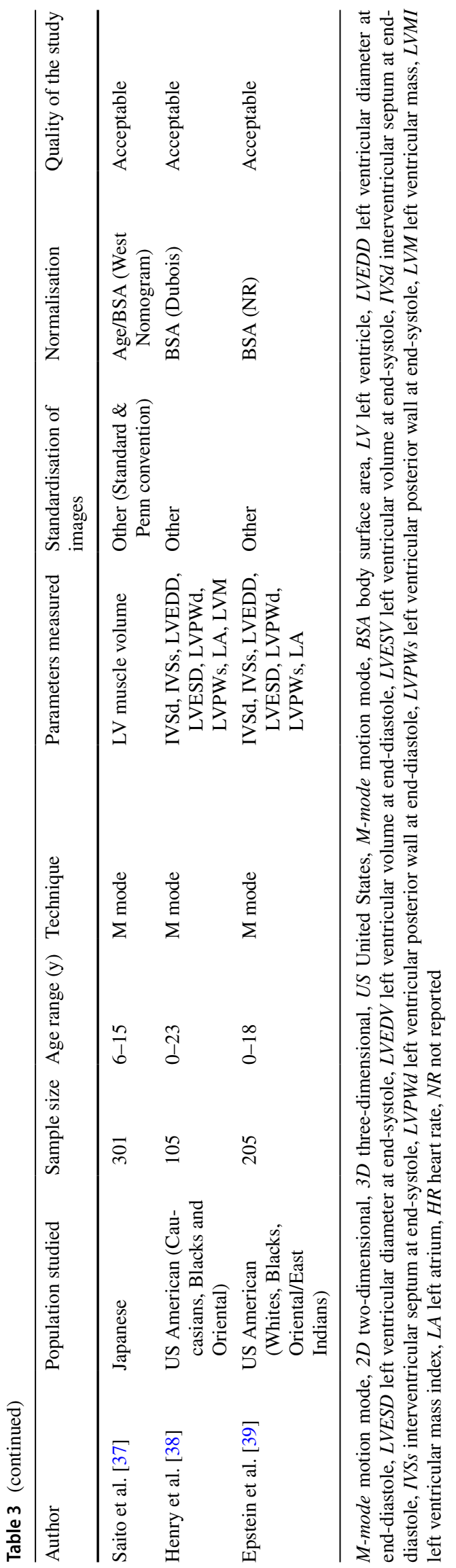

\section{Left Atrium Dimensions}

LA diameter references were established in twelve studies, six of which were conducted in US American children [16, $28,30,38,39]$. LA length references were from Indian, Italian and Swedish children and of these, two studies also reported data on LA area [5, 9, 32]. LA volume was derived in four studies and three of these were in US American children (Table 3) [12, 14, 21, 30].

\section{Comparison of LV and LA Dimension Between Studies}

Reference values of selected cardiac measures from different racial groups which used M-mode technique and normalised results with BSA were identified and compared (Tables 4, 5 ). The $p$ values for the compared references are shown in Supplementary Tables 1 and 2 and these are for $z$ score $=0$ and +2 distributions. The graphical representations of the distributions for the selected cardiac measures are shown in Supplementary Figs. 1 and 2. Mean left ventricular diameter at end-diastole (LVEDD) among US American children and German children was similar $(p=0.906)$. On the other hand, Zimbabwean children had thicker mean interventricular septum at end-diastole (IVSd) than German children had $(p<0.001)$ while US American children and German children were similar $(p=0.281)$. Mean LA diameter was also similar between British and German children $(p=0.699)$.

Comparison using predicted values of $z$ score $=+2$ (cutoff for upper limit of normal), significant differences were noted in the IVSd measures between Zimbabwean and German children $(p=0.001)$. IVSd measures between German and US American children were significantly different $(p<0.001)$. No significant differences were noted on the distributions of LA measures between the compared studies. The predicted values of $z$ score $=+2$ by Kampmann et al. progressed in a step-wise fashion so for example, a value of IVSd $>10.4 \mathrm{~mm}$ had a $z$ score $=+2$ for BSA between 1.7 and $1.9 \mathrm{~m}^{2}$. The shape of Kampmann's distribution for $z$ score $=+2$ was therefore strikingly different from the other references [23].

\section{Discussion}

Accurate assessment of left cardiac chamber size in children relies on the availability of representative reference ranges. In this study, we have systematically reviewed differences between reference ranges for LV and LA chamber dimensions in children and adolescents. We found many studies which have established reference ranges for LV and LA chamber dimensions, reflecting the significant interest in, and importance of, establishing reference ranges 
Table 4 A comparison of published echocardiographic normal references for LV dimensions in studies using M-mode and normalised to BSA (for a child with $1 \mathrm{~m}^{2} \mathrm{BSA}$ )

\begin{tabular}{|c|c|c|c|c|c|c|c|c|}
\hline Author & $\begin{array}{l}\text { Population } \\
\text { studied }\end{array}$ & $\begin{array}{l}\text { Method for } \\
\text { BSA }\end{array}$ & $\operatorname{LVEDD}(\mathrm{mm})$ & $\operatorname{LVESD}(\mathrm{mm})$ & IVSd (mm) & IVSs (mm) & $\begin{array}{l}\text { LVPWd } \\
(\mathrm{mm})\end{array}$ & LVPWs (mm) \\
\hline $\begin{array}{l}\text { Gokhroo et al. } \\
\text { [5] }\end{array}$ & Indian & Haycock & $\begin{array}{l}35.02(27.02- \\
42.04)\end{array}$ & $\begin{array}{l}21.32(13.81- \\
28.84)\end{array}$ & $7.4(5.5-9.3)$ & $\begin{array}{l}11.0(8.11- \\
13.9)\end{array}$ & $7.2(5.4-9.1)$ & $\begin{array}{l}10.8(10.1- \\
11.5)\end{array}$ \\
\hline $\begin{array}{r}\text { Cantinotti } \\
\text { et al. [9] }\end{array}$ & Italian & Haycock & $\begin{array}{l}37.86(31.56- \\
45.42)\end{array}$ & $\begin{array}{l}22.97(17.46- \\
30.20)\end{array}$ & & & & \\
\hline $\begin{array}{l}\text { Majonga et al. } \\
\text { [6] }\end{array}$ & Zimbabwean & Dubois & $\begin{array}{l}37.10(32.43- \\
41.76)\end{array}$ & $\begin{array}{l}25.29(20.84- \\
29.74)\end{array}$ & $7.0(5.0-9.1)$ & $9.2(6.7-11.6)$ & $6.8(5.2-8.5)$ & $9.0(6.5-11.4)$ \\
\hline $\begin{array}{l}\text { Pettersen et al. } \\
\text { [16] }\end{array}$ & US American & Dubois & $\begin{array}{l}39.09(32.06- \\
48.79)\end{array}$ & $\begin{array}{l}25.1(19.6- \\
32.1)\end{array}$ & $5.9(3.9-9.0)$ & $8.6(6.0-12.3)$ & $5.4(3.7-7.9)$ & $10.3(7.7-13.9)$ \\
\hline $\begin{array}{r}\text { Kampmann } \\
\text { et al. [23] }\end{array}$ & German & Dubois & $\begin{array}{l}38.50(31.70- \\
45.30)\end{array}$ & $\begin{array}{l}24.4(18.6- \\
30.2)\end{array}$ & $5.8(4.0-7.6)$ & $8.4(5.1-11.7)$ & $5.9(3.7-8.1)$ & $9.5(6.8-12.2)$ \\
\hline $\begin{array}{l}\text { Huwez et al. } \\
{[26]}\end{array}$ & British & Dubois & $\begin{array}{l}38.27(33.05- \\
43.49)\end{array}$ & $\begin{array}{l}24.28(19.79- \\
28.77)\end{array}$ & $7.1(5.2-7.1)$ & & $6.4(4.6-8.3)$ & \\
\hline
\end{tabular}

Dimensions are mean $( \pm 2 \mathrm{SD})$

US United States, $M$-mode motion mode, $B S A$ body surface area, $L V$ left ventricle, $L V E D D$ left ventricular diameter at end-diastole, $L V E S D$ left ventricular diameter at end-systole, IVSd interventricular septum at end-diastole, IVSs interventricular septum at end-systole, $L V P W d$ left ventricular posterior wall at end-diastole, $L V P W s$ left ventricular posterior wall at end-systole, $L V M$ left ventricular mass

Table 5 A comparison of published echocardiographic normal references for LA dimensions in studies using M-mode and normalised to BSA (for a child with $1 \mathrm{~m}^{2} \mathrm{BSA}$ )

\begin{tabular}{llllr}
\hline Author & Population studied & Technique & Method for BSA & LA diameter (mm) \\
\hline Majonga et al. [6] & Zimbabwean (Blacks) & M-mode & Dubois & $24.05(19.19-28.91)$ \\
Huwez et al. [26] & British & M-mode & Dubois & $25.9(20.3-31.6)$ \\
Kampmann et al. [23] & German (Caucasian) & M-mode & Dubois & $25(19.2-30.8)$ \\
\hline
\end{tabular}

Dimensions are mean $( \pm 2 \mathrm{SD})$

US United States, $M$-mode motion mode, $B S A$ body surface area, $2 D$ two-dimensional, $L A$ left atrium, $A 4 C$ apical four chamber view

for chamber dimensions in children. Most of the reference ranges in children were, however, developed in European and North American (US populations) and mainly in Caucasians. Notably, there was only one study each from South America (Brazil) and Africa (Zimbabwe) and the latter was published very recently, implying that most African countries rely on Western references in clinical practice which may not accurately represent black African children [6, 19].

Comparability of the available reference ranges was limited due to substantial methodological variations, including parameters of normalisation; technique of image acquisition (e.g. 2D or M-mode); measured chamber dimension and/or method used for performing the measurements (e.g. ASE guidelines or other). Cantinotti et al. highlighted that it is imperative to standardise methods of image acquisition and consistency in normalisation of the references [40].

However, we were able to compare a few studies which used similar methods from different races for selected cardiac measures. There were notable differences in some of the measures, particularly interventricular septal thickness among Zimbabwean, German and US American children.
Differences between Zimbabwean and German children were consistently demonstrated at both mean-level and upper cut-off for normal distributions. Although no interventricular septal thickness difference was found in the mean distribution of German and US American children, it was evident in the predicted values $z$ score $=+2$. In practice, it is the upper cut-off for normal which is used to define abnormality rather than the mean. Our findings suggest that differences in reference ranges between different racial groups do exist but may be overlooked because of the scarcity of data e.g. African children. The use of inappropriate reference ranges may result in either under- or over-diagnosis of cardiac abnormalities or missing of early cardiac chamber remodelling due to cardiac disease [41]. This highlights the importance of using racial-specific reference ranges in clinical practice.

In a recently published study on effect of age, sex, race and ethnicity in echocardiographic $z$ scores of children, significant effects by all the four parameters were observed on $z$ scores. However, the authors concluded that these were not of clinical significance [4]. Given that this study was conducted mainly in US American and Canadian children, findings cannot be 
generalisable to the rest of the world due to non-standardisation of methods in the available references. There are also other geographical confounders such as nutrition and altitude which may affect cardiovascular development [4].

Most studies used the M-mode or 2D echocardiography techniques. Advanced techniques such as 3D echocardiography, which may overcome some of the technical challenges of angle dependence and other geometric assumptions associated with conventional techniques, should be used to more accurately quantify chamber sizes and development of reference ranges [42].

This study is limited by the fact that many of the studies did not report the actual race of the children, and we therefore made assumptions based on the country the study was conducted in. We compared very broad racial groups due to scarcity of data. In addition, we were unable to compare references for other cardiac measures due to varying methods used in the studies. However, in the few selected references and cardiac measures where this was possible, we were able to demonstrate significant differences in different races. We also showed similarities in same racial groups. It is also highly likely that in addition to the varying methods used in other studies, racial differences are also present.

\section{Conclusion}

This review underlines the importance of using race-specific reference ranges for children, as well as the need for standardising echocardiographic methods in deriving those reference ranges. Furthermore, these reference ranges need to be comprehensive, including a wide range of cardiac measures, as some studies only reported normal values for a single cardiac measure. Future studies should focus on including 3D parameters in addition to $2 \mathrm{D}$ and $\mathrm{M}$-mode.

Funding This study was funded by the Wellcome Trust (Grant Number 095878/Z/11/Z).

\section{Compliance with Ethical Standards}

Conflict of interest On behalf of all authors, the corresponding author states that there is no conflict of interest.

Ethical Approval All procedures performed in the studies involving human participants were in accordance with the ethical standards of the institutional and/or national research committee and with the 1964 Helsinki declaration and its later amendments or comparable ethical standards.

Open Access This article is distributed under the terms of the Creative Commons Attribution 4.0 International License (http://creativeco mmons.org/licenses/by/4.0/), which permits unrestricted use, distribution, and reproduction in any medium, provided you give appropriate credit to the original author(s) and the source, provide a link to the Creative Commons license, and indicate if changes were made.

\section{References}

1. Echocardiographic Normal Ranges Meta-Analysis of the Left Heart C (2015) Ethnic-specific normative reference values for echocardiographic LA and LV size, LV mass, and systolic function: the EchoNoRMAL Study. JACC Cardiovasc Imaging 8:656-665

2. Pfaffenberger S, Bartko P, Graf A, Pernicka E, Babayev J, Lolic E, Bonderman D, Baumgartner H, Maurer G, Mascherbauer J (2013) Size matters! Impact of age, sex, height, and weight on the normal heart size. Circ Cardiovasc Imaging 6:1073-1079

3. Wells G, Shea B, O'connell D, Peterson J, Welch V, Losos M, Tugwell P (2011) The Newcastle-Ottawa Scale (nos) for assessing the quality of nonrandomised studies in meta-analyses. [Internet]. Ottawa Hospital Research Institute, Ottawa

4. Lopez L, Colan S, Stylianou M, Granger S, Trachtenberg F, Frommelt P, Pearson G, Camarda J, Cnota J, Cohen M, Dragulescu A, Frommelt M, Garuba O, Johnson T, Lai W, Mahgerefteh J, Pignatelli R, Prakash A, Sachdeva R, Soriano B, Soslow J, Spurney C, Srivastava S, Taylor C, Thankavel P, van der Velde M, Minich L (2017) Relationship of echocardiographic $\mathrm{Z}$ Scores adjusted for body surface area to age: the pediatric heart network normal echocardiogram database, Circ Cardiovasc Imaging 10: e006979

5. Gokhroo RK, Anantharaj A, Bisht D, Kishor K, Plakkal N, Aghoram R, Mondal N, Pandey SK, Roy R (2017) A pediatric echocardiographic Z-score nomogram for a developing country: Indian pediatric echocardiography study - the Z-score. Ann Pediatr Cardiol 10:31-38

6. Majonga ED, Rehman AM, McHugh G, Mujuru HA, Nathoo K, Patel MS, Munyati S, Odland JO, Kranzer K, Kaski JP, Ferrand RA (2017) Echocardiographic reference ranges in older children and adolescents in sub-Saharan Africa. Int J Cardiol 248:409-413

7. Foster BJ, Khoury PR, Kimball TR, Mackie AS, Mitsnefes M (2016) New reference centiles for left ventricular mass relative to lean body mass in children. J Am Soc Echocardiogr 29:441-447

8. Chinali M, Emma F, Esposito C, Rinelli G, Franceschini A, Doyon A, Raimondi F, Pongiglione G, Schaefer F, Matteucci MC (2016) Left ventricular mass indexing in infants, children, and adolescents: a simplified approach for the identification of left ventricular hypertrophy in clinical practice. J Pediatr 170:193-198

9. Cantinotti M, Scalese M, Murzi B, Assanta N, Spadoni I, De Lucia V, Crocetti M, Cresti A, Gallotta M, Marotta M, Tyack K, Molinaro S, Iervasi G (2014) Echocardiographic nomograms for chamber diameters and areas in Caucasian children. J Am Soc Echocardiogr 27:1279

10. Oran B, Bodur AS, Arslan D, Cimen D, Guvenc O (2014) Normal M mode values in healthy Turkish children. Turk J Med Sci 44:756-763

11. Motz R, Schumacher M, Nurnberg J, Viemann M, Grafmuller S, Fiedler K, Claus M, Kronberg K (2014) Echocardiographic measurements of cardiac dimensions correlate better with body length than with body weight or body surface area. Pediatr Cardiol 35:1327-1336

12. Bhatla P, Nielsen JC, Ko HH, Doucette J, Lytrivi ID, Srivastava S (2012) Normal values of left atrial volume in pediatric age group using a validated allometric model. Circ Cardiovasc Imaging 5:791-796

13. Kervancioglu P, Kervancioglu M, Tuncer MC, Hatipoglu ES (2011) Left ventricular mass in normal children and its correlation with weight, height and body surface area. Int J Morphol 29:982-987

14. Taggart NW, Cetta F, O'Leary PW, Seward JB, Eidem BW (2010) Left atrial volume in children without heart disease and in those 
with ventricular septal defect or patent ductus arteriosus or hypertrophic cardiomyopathy. Am J Cardiol 106:1500-1504

15. Khoury PR, Mitsnefes M, Daniels SR, Kimball TR (2009) Agespecific reference intervals for indexed left ventricular mass in children. J Am Soc Echocardiogr 22:709-714

16. Pettersen MD, Du W, Skeens ME, Humes RA (2008) Regression equations for calculation of $\mathrm{Z}$ scores of cardiac structures in a large cohort of healthy infants, children, and adolescents: an echocardiographic study. J Am Soc Echocardiogr 21:922-934

17. Foster BJ, Mackie AS, Mitsnefes M, Ali H, Mamber S, Colan SD (2008) A novel method of expressing left ventricular mass relative to body size in children. Circulation 117:2769-2775

18. Poutanen T, Jokinen E (2007) Left ventricular mass in 169 healthy children and young adults assessed by three-dimensional echocardiography. Pediatr Cardiol 28:201-207

19. Bonatto RC, Fioretto JR, Okoshi K, Matsubara BB, Padovani CR, Manfrin TCR, Gobbi M, Martino RS, Bregagnollo EA (2006) Percentile curves of normal values of echocardiographic measurements in normal children from the central-southern region of the State of Sao Paulo, Brazil. Arq Bras Cardiol 87:711-721

20. Overbeek LIH, Kapusta L, Peer PGM, de Korte CL, Thijssen JM, Daniels O (2006) New reference values for echocardiographic dimensions of healthy Dutch children. Eur J Echocardiogr 7:113 $-21$

21. Poutanen T, Jokinen E, Sairanen H, Tikanoja T (2003) Left atrial and left ventricular function in healthy children and young adults assessed by three dimensional echocardiography. Heart 89:544-549

22. Brangenberg R, Burger A, Romer U, Kozlik-Feldmann R, Netz H (2002) Echocardiographic assessment of left ventricular size and function in normal children from infancy to adolescence: acoustic quantification in comparison with traditional echocardiographic techniques. Pediatr Cardiol 23:394-402

23. Kampmann C, Wiethoff CM, Wenzel A, Stolz G, Betancor M, Wippermann CF, Huth RG, Habermehl P, Knuf M, Emschermann T, Stopfkuchen H (2000) Normal values of M mode echocardiographic measurements of more than 2000 healthy infants and children in central Europe. Heart 83:667-672

24. Daubeney PEF, Blackstone EH, Weintraub RG, Slavik Z, Scanlon J, Webber SA (1999) Relationship of the dimension of cardiac structures to body size: an echocardiographic study in normal infants and children. Cardiol Young 9:402-410

25. Daniels SR, Kimball TR, Morrison JA, Khoury P, Meyer RA (1995) Indexing left ventricular mass to account for differences in body size in children and adolescents without cardiovascular disease. Am J Cardiol 76:699-701

26. Huwez FU, Houston AB, Watson J, McLaughlin S, Macfarlane PW (1994) Age and body surface area related normal upper and lower limits of $\mathrm{M}$ mode echocardiographic measurements and left ventricular volume and mass from infancy to early adulthood. $\mathrm{Br}$ Heart J 72:276-280

27. Malcolm DD, Burns TL, Mahoney LT, Lauer RM (1993) Factors affecting left ventricular mass in childhood: the Muscatine study. Pediatrics 92:703-709

28. Nidorf SM, Picard MH, Triulzi MO, Thomas JD, Newell J, King ME, Weyman AE (1992) New perspectives in the assessment of cardiac chamber dimensions during development and adulthood. J Am Coll Cardiol 19:983-988

29. Vogel M, Staller W, Buhlmeyer K (1991) Left ventricular myocardial mass determined by cross-sectional echocardiography in normal newborns, infants, and children. Pediatr Cardiol 12:143-149

30. Pearlman JD, Triulzi MO, King ME, Abascal VM, Newell J, Weyman AE (1990) Left atrial dimensions in growth and development: normal limits for two-dimensional echocardiography. J Am Coll Cardiol 16:1168-1174

31. Pearlman JD, Triulzi MO, King ME, Newell J, Weyman AE (1988) Limits of normal left ventricular dimensions in growth and development: Analysis of dimensions and variance in the twodimensional echocardiograms of 268 normal healthy subjects. J Am Coll CardioI 12:1432-1441

32. Hanseus K, Bjorkhem G, Lundstrom NR (1988) Dimensions of cardiac chambers and great vessels by cross-sectional echocardiography in infants and children. Pediatr Cardiol 9:7-15

33. Daniels SR, Meyer RA, Liang YC, Bove KE (1988) Echocardiographically determined left ventricular mass index in normal children, adolescents and young adults. J Am Coll Cardiol 12:703-708

34. Akiba T, Yoshikawa M, Otaki S, Kobayashi Y, Nakasato M, Suzuki H, Tetsuo S (1986) Echocardiographic measurements of left ventricle in normal infants and children. Tohoku J Exp Med 149:31-37

35. Voogd PJ, Rijsterborgh H, Lubsen J, Arntzenius AC, Monsjou LK, Godijn EH (1984) Reference ranges of echocardiographic measurements in the Dutch population. Eur Heart J 5:762-70

36. Henry WL, Gardin IM, Ware JH (1980) Echocardiographic measurements in normal subjects from infancy to old age. Circulation 62:1054-1061

37. Saito M, Mori C, Nishio T (1978) Normal values of echocardiography in pediatrics. I. Left ventricular muscle volume (LVMV). The Shimane heart study. Shimane J Med Sci 2:63-69

38. Henry WL, Ware J, Gardin JM, Hepner SI, Mckay J, Weiner M (1978) Echocardiographic measurements in normal subjects. Growth-related changes that occur between infancy and early adulthood. Circulation 57:278-285

39. Epstein ML, Goldberg ST, Allen HD, Konecke L, Wood J (1975) Great vessel, cardiac chamber, and wall growth patterns in normal children. Circulation 51:1124-1129

40. Cantinotti M, Kutty S, Franchi E, Paterni M, Scalese M, Iervasi G, Koestenberger M (2017) Pediatric echocardiographic nomograms: what has been done and what still needs to be done. Trends Cardiovasc Med 27:336-349

41. Badano LP (2014) Ethnicity: a missing variable when defining normative values for reporting echocardiographic studies. Arch Cardiovasc Imaging 2(1):2

42. Lang RM, Badano LP, Tsang W, Adams DH, Agricola E, Buck T, Faletra FF, Franke A, Hung J, de Isla LP (2012) EAE/ASE recommendations for image acquisition and display using threedimensional echocardiography. Eur Heart J Cardiovasc Imaging $13: 1-46$ 